\title{
Local Wisdoms in Bengkulu Play Script "Sayembara Putri Gading Cempaka" by Agus Setiyanto
}

\section{Dedi Febriyanto ${ }^{1}$, Mulyanto Widodo ${ }^{2}$}

Universitas Lampung, Lampung, Indonesia

Universitas Lampung, Lampung, Indonesia

\begin{tabular}{|c|c|}
\hline Article History & Abstract \\
\hline $\begin{array}{r}\text { Submitted date: } \\
\text { 2021-07-30 } \\
\text { Accepted date: } \\
2021-11-15 \\
\text { Published date: } \\
2021-11-24 \\
\end{array}$ & $\begin{array}{l}\text { The purpose of this research is to describe the local wisdom in the Bengkulu play script } \\
\text { "Sayembara Putri Gading Cempaka" by Agus Setiyanto. This study used a descriptive } \\
\text { qualitative method with a sociological approach. The data of this research are words, } \\
\text { sentences, and discourses in the local wisdom of the Bengkulu play script Sayembara } \\
\text { Putri Gading Cempaka written by Agus Setiyanto. The data were collected by the read- }\end{array}$ \\
\hline $\begin{array}{l}\text { Keywords: } \\
\text { local wisdom; play script; } \\
\text { sayembara putri gading } \\
\text { cempaka }\end{array}$ & $\begin{array}{l}\text { the data could be triangularly validated with the data source. The data analysis was done } \\
\text { by the content analysis technique method. The results showed that Agus Setiyanto's } \\
\text { Bengkulu play Sayembara Putri Gading Cempaka had various local wisdoms. The } \\
\text { local wisdom covered tangible local wisdom; (1) taboos and obligations of a leader, (2) } \\
\text { traditions, (3) values, (4) advice, (5) way of life, and (6) local languages. }\end{array}$ \\
\hline
\end{tabular}

\section{Kata Kunci:}

kearifan lokal; naskah sandiwara; sayembara putri gading cempaka

\section{Abstrak}

Kearifan Lokal dalam Naskah Sandiwara Bengkulu Sayembara Putri Gading Cempaka Karya Agus Setiyanto

Tujuan penelitian ini adalah mendeskripsikan kearifan lokal dalam naskah sandiwara Bengkulu Sayembara Putri Gading Cempaka karya Agus Setiyanto. Penelitian ini menggunakan metode kualitatif deskriptif dengan pendekatan sosiologi. Data penelitian ini adalah kata, kalimat, dan wacana yang memuat kearifan lokal dalam naskah sandiwara Bengkulu Sayembara Putri Gading Cempaka karya Agus Setiyanto. Pengumpulan data dilakukan menggunakan teknik baca-catat. Pengumpulan dan penganalisisan data dilakukan dengan cara bersamaan agar data tersebut dapat divalidasi secara trianggulasi dengan sumber data. Adapun analisis data dilakukan dengan metode teknik analisis isi. Hasil Penelitian menunjukkan bahwa naskah sandiwara Bengkulu Sayembara Putri Gading Cempaka karya Agus Setiyanto mengandung kearifan lokal yang sangat beragam. Adapun kearifan lokal yang dimaksud meliputi kearifan lokal berwujud; (1) pantangan dan kewajiban seorang pemimpin, (2) tradisi, (3) nilai, (4) nasihat, (5) pandangan hidup, dan (6) bahasa daerah.

\section{Pendahuluan}

Karya sastra merupakan produk masyarakat yang selalu menampilkan gambaran kehidupan, sedangkan kehidupan itu sendiri adalah suatu kenyataan sosial (Damono, 2012). Karya sastra sebagai

Corresponding author:

${ }^{1}$ dedifebri97@gmail.com 
Febriyanto, D. \& Widodo, M., (2021). Local Wisdom in Bengkulu Play Script "Sayembara Putri Gading Cempaka” by Agus Setiyanto. LITE: Jurnal Bahasa, Sastra, dan Budaya $17 \quad$ (2), 150-159. https://doi.org/10.33633/lite.v17i2.5049

produk dari masyarakat memiliki kedudukan dan fungsi yang cukup penting di tengah kehidupan. Karya sastra sarat akan nilai-nilai yang dapat membentuk peradaban masyarakat luhur dan bermartabat. Melalui pengamalan nilai yang terkandung di dalam karya sastra, masyarakat akan mampu memahami diri, keadaan sosial, serta menghadapi segala persolan hidup dengan cara yang lebih luwes dan bijak. Selain itu, hal yang tak kalah penting adalah bahwa pada akhirnya nilai yang terkandung di dalam sebuah karya sastra dapat dijadikan sebagai salah satu pedoman kehidupan yang universal.

Sebagaimana telah dikemukakan bahwa karya sastra sarat akan nilai. Salah satu wujud nilai yang terkandung dalam karya sastra adalah kearifan lokal. Wibowo (Kasmi, 2019) mengungkapkan bahwa kearifan lokal merupakan identitas budaya sebuah bangsa yang menyebabkan bangsa tersebut mampu menyerap dan mengolah kebudayaan yang berasal dari luar sesuai dengan karakternya sendiri. Kearifan lokal juga dapat diartikan sebagai gagasan setempat yang bersifat bijaksana, penuh kearifan, bernilai baik, yang tertanam dan diikuti oleh masyarakatnya (Maemunah, 2019; Hasanah, 2016; Sartini, 2004). Kearifan lokal merupakan nilai-nilai yang dianut oleh suatu masyarakat tertentu dalam kehidupan sehari-hari (Mariane, 2014; (Gasong et al., 2015). Kearifan lokal adalah usaha manusia dengan menjadikan akal budinya sebagai landasan dalam bertindak (Ridwan, 2007). Kearifan lokal itu sendiri merupakan produk dari masyatakat yang dapat berbentuk bendawi maupun nonbendawi. Kearifan lokal digunakan sebagai rujukan bagi masyarakat dalam berinteraksi dan berkomunikasi, baik dengan sesama manusia, alam, maupun dengan Tuhan (Yetti, 2019; Muchtar, 2009).

Drama dikelompokkan sebagai salah satu karya sastra karena menggunakan media bahasa (Tsai et al., 2016). Drama adalah karya sastra yang bertujuan menggambarkan kehidupan dengan mengemukakan tikaian dan emosi lewat lakuan dan dialog (Gemtou, 2014). Naskah drama sebagai salah satu genre sastra mengandung banyak kearifan lokal yang dapat dijadikan sebagai media penanaman nilai dalam kehidupan. Terlebih drama merupakan salah satu genre sastra yang dalam menggambarkan pesan-pesannya melalui perilaku atau gerak-gerik para tokoh sehingga pembaca atau penikmat drama tidak merasa sedang digurui secara langsung. Keadaan tersebut tentunya akan membuat penikmat drama lebih mudah menerima pesan-pesan yang hendak disampaikan oleh pengarang.

Adapun salah satu naskah drama yang kaya akan kearifan lokalnya adalah sebuah naskah sandiwara Bengkulu berjudul Sayembara Putri Gading Cempaka yang ditulis oleh Agus Setiyanto. Naskah drama ini merupakan salah satu naskah yang terdapat dalam kumpulan naskah sandiwara Bengkulu Panggung Bangsawan. Naskah tersebut banyak mengangkat budaya lokal masyarakat sehingga sangat layak untuk dikaji secara mendalam. Pengarang membingkai keberagaman kearifan lokal tersebut dengan cara mengangkat latar masa lalu yang istanasentris. Pengarang juga membumbui naskah tersebut dengan menampilkan segala dinamika intrik politik yang marak dijumpai dalam kehidupan moderen seperti saat ini.

Berkenaan dengan kajian kearifan lokal, peneliti menemukan beberapa penelitian terdahulu yang relevan dengan penelitian ini. Beberapa penelitian tersebut antara lain pernah dilakukan oleh Wildan (2020) yang mengkaji kearifan lokal dalam novel Seulusoh karya D. Kemalawati. Selanjutnya penelitian yang dilakukan Jayapada \& Kiptiyah (2017), mengkaji kearifan lokal dalam cerita rakyat sebagai salah satu media pendidikan karakter untuk membentuk moral peserta didik. Penelitian relevan berikutnya dilakukan oleh Kasmi (2019), mengkaji nilai kearifan lokal yang terkandung di dalam novel Tempat Paling Sunyi karya Arafat Nur. Penelitian berikutnya dilakukan Febriyanto et al.(2021), mengkaji kearifan lokal dalamhikayat Komering pitu phuyang. Penelitian relevan terakhir dilakukan oleh Lubis et al. (2021), mengkaji nilai kearifan lokal dalam novel Mangalua karya Idris Pasaribu.

Penelitian relevan yang telah dikemukakan di atas memiliki kesamaan dari segi fokus penelitian, sama-sama mengkaji kearifan lokal. perbedaan mendasar terletak pada sumber data kajian. Penelitian ini memilih naskah sandiwara Bengkulu Sayembara Putri Gading Cempaka karya Agus Setiyanto, 
Febriyanto, D. \& Widodo, M., (2021). Local Wisdom in Bengkulu Play Script "Sayembara Putri Gading Cempaka” by Agus Setiyanto. LITE: Jurnal Bahasa, Sastra, dan Budaya $17 \quad$ (2), 150-159. https://doi.org/10.33633/lite.v17i2.5049

sedangkan penelitian terdahulu banyak yang menggunakan novel atau cerpen. Hal ini sekaligus menjadi salah satu pertimbangan peneliti dalam memilih sumber data penelitian. Peneliti memandang perlunya mengkaji naskah drama karena genre sastra ini mampu memberikan pengaruh yang jauh lebih luas kepada penikmat sastra melebihi karya sastra lainnya. Hal ini dikarenakan selain dituangkan dalam tulisan, drama juga dilakonkan di panggung-panggung sandiwara. Oleh karena itu, sudah sepatutnya naskah drama mendapatkan perhatian lebih besar dalam pengkajiannya.

Berdasarkan pemaparan di atas, peneliti terdorong untuk melakukan kajian kearifan lokal dalam naskah sandiwara Bengkulu Putri Gading Cempaka karya Agus Setiyanto. Kearifan lokal yang dikaji meliputi pandangan hidup, nasihat, nilai-nilai, kedaerahan, dan lain-lain. Hasil penelitian ini diharapkan dapat semakin membuka wawasan pembaca tentang keberagaman yang dimiliki bangsa Indonesia. Keberagaman merupakan anugerah Tuhan yang sudah selayaknya dijaga dan dilestarikan bersama-sama.

\section{Metode}

Penelitian ini menggunakan metode deskriptif kualitatif dengan pendekatan sosiologi sastra. Data penelitian ini adalah kata, kalimat, dan wacana yang memuat kearifan lokal dalam naskah sandiwara Bengkulu Sayembara Putri Gading Cempaka karya Agus Setiyanto. Pengumpulan data dilakukan dengan teknik baca-catat. Pengumpulan dan penganalisisan data dilakukan dengan cara bersamaan agar data tersebut dapat divalidasi secara trianggulasi dengan sumber data. Analisis data dilakukan dengan metode teknik analisis isi. Teknik ini digunakan untuk menggali beragam kearifan lokal yang terkandung di dalam naskah sandiwara.

\section{Hasil dan Pembahasan}

Naskah sandiwara Bengkulu Sayembara Putri Gading Cempaka menceritakan sebuah sayembara yang diadakan sebuah kerajaan bernama Sungai Serut. Sayembara tersebut diadakan untuk memperebutkan seorang putri kebanggaan kerajaan Sungai Serut, Putri Gading Cempaka. "Siapa yang dapat memikat hati Putri Gading Cempaka, maka ia akan didaulat menjadi suami sang putri sekaligus menjadi raja di kerajaan Sungai Serut!" kira-kira demikianlah bunyi sayembara yang telah tersebar hingga ke negeri seberang.

Berdasarkan penelitian yang dilakukan, ditemukan beberapa jenis kearifan lokal di dalam naskah sandiwara Bengkulu Sayembara Putri Gading Cempaka karya Agus Setiyanto. Beragam wujud kearifan lokal tersebut akan dituangkan dalam tabel 1 berikut.

Tabel 1: Kearifan Lokal dalam Naskah Sandiwara Bengkulu SPGC

\begin{tabular}{|c|c|c|}
\hline No. & Kearifan Lokal & Keterangan \\
\hline 1 & Pantangan dan kewajiban & Ada \\
\hline 2 & Tradisi & Ada \\
\hline 3 & Nilai & Ada \\
\hline 4 & Nasihat & Ada \\
\hline 5 & Pandangan hidup & Ada \\
\hline 6 & Bahasa Daerah & Ada \\
\hline
\end{tabular}

\subsection{Kearifan Lokal Berwujud Pantangan dan Kewajiban}

Sebuah kerajaan tidak dapat dilepaskan dari keberadaan seorang raja. Raja adalah pemimpin tertinggi yang mengemban amanat seluruh rakyatnya. Seorang raja sudah sepatutnya memiliki kemampuan sekaligus kesanggupan dalam menunaikan seluruh kewajiban yang sudah menjadi tanggung jawabnya. Kearifan lokal dalam wujud pantangan dan kewajiban seorang pemimpin yang dalam hal ini adalah seorang raja, dapat dilihat melalui kutipan berikut. 
Febriyanto, D. \& Widodo, M., (2021). Local Wisdom in Bengkulu Play Script "Sayembara Putri Gading Cempaka” by Agus Setiyanto. LITE: Jurnal Bahasa, Sastra, dan Budaya $17 \quad$ (2), $150-159$. $\underline{\text { https://doi.org/10.33633/lite.v17i2.5049 }}$

\section{SULTAN ISKANDAR NAN TUA}

Yha Dekrit. Tapi, sebelumnya, seperti biasanya, saya ingin mendengarkan laporan umum daripada kalian semua. Baiklah, sekarang diawali daripada laporan Panglima selaku penanggungjawab secara umum daripada ketentraman negeri ini. Silahkan Panglima! (Setiyanto, 2006:4)

Kutipan di atas menggambarkan wujud tanggung jawab dan ketegasan seorang raja. Pada data tersebut terlihat bahwa sebelum sang raja mengumumkan sebuah dekrit atau sebuah keputusan mengenai suatu hal, sang raja terlebih dahulu ingin mendengar laporan dari seluruh pejabat kerajaannya mengenai kondisi kerajaan, termasuk di antaranya adalah keadaan masyarakat, ketersediaan pangan, dan lain sebagainya.

Sikap tersebut menunjukkan bahwa sang raja telah melaksanakan kewajibannya dengan penuh kesadaran. Sang raja juga terlihat mengutamakan kepentingan rakyatnya daripada dirinya sendiri. Sikap egois dengan tidak memedulikan nasib rakyat juga kerajaannya tentunya menjadi pantangan tersendiri bagi sang raja. Sikap tersebut sangat tidak layak dimiliki oleh seorang pemimpin. Sikap bijaksana sebagaimana yang digambarkan Sultan Iskandar Nan Tua selayaknya dapat dijadikan teladan untuk pemimpin negeri. Rakyat menjadi prioritas utama yang harus diperhatikan kesejahteraannya.

Kearifan lokal berwujud pantangan juga tersurat dalam percakapan yang terjadi antara Pangeran Muda dan Orang Kaya ketika mereka melewati sebuah sungai yang kotor. Berikut ini data yang menggambarkan percakapan antara Pangeran Muda dan Orang Kaya.

\section{PANGERAN MUDA}

Sungai Serut, ya ya ya ya. tapi

Orangkaya, kenapa sungai ini kotor sekali? Dan banyak empangnya. (Setiyanto, 2006:21)

\section{PANGERAN MUDA}

Yha, menurut pengamatan saya, tampaknya masyarakat pribumi di sini memang kurang memperhatikan ekologi lingkungan. (Setiyanto, 2006:21-22)

Kutipan di atas menggambarkan keprihatinan Pangeran Muda terhadap keadaan sungai kepunyaan negeri Sungai Serut yang sangat kotor. Kutipan di atas juga menyiratkan sebuah pantangan bagi pihak Pangeran Muda. Tindakan mengotori sungai adalah sebuah pantangan yang pelakunya akan mendapatkan hukuman berat. Menjaga ekologi lingkungan agar tetap stabil adalah tugas bersama yang harus senantiasa dijalankan dengan penuh kesadaran dan tanggung jawab. Menjaga lingkungan sejatinya sama dengan menjaga kehidupan itu sendiri. Hal ini dikarenakan rusaknya lingkungan akan berdampak buruk pula bagi manusia.

\subsection{Kearifan Lokal Berwujud Tradisi}

Kearifan lokal dalam naskah sandiwara Sayembara Putri Gading Cempakajuga berwujud tradisi. Tradisi yang dimaksud adalah tradisi khas kerajaan, yang tidak ada di jaman modern seperti saat ini. Kearifan lokal yang dimaksud dapat dilihat melalui kutipan berikut.

\section{BUNDA RATU}

Nanda Bungsu,.... memang nanda Bungsu Bunda panggil, sebab kita mau membahas mengenai apa yang telah diwasiatkan oleh Ayahanda sekalian, .... bukankah sebelum meninggal, Ayahanda kalian memberikan wasiatnya, agar kita mengadakan sayembara untuk memperebutkan nanda Bungsu... dan bagi siapa saja yang berhasil memikat nanda Bungsu, maka dialah yang berhak menduduki tahta kerajaan Sungai Serut ini. Dan sekaligus mendapatkan permaisuri nanda Bungsu... oleh sebab itulah nanda Bungsu harus ikut andil memberikan suaranya. (Setiyanto, 2006:43) 
Febriyanto, D. \& Widodo, M., (2021). Local Wisdom in Bengkulu Play Script "Sayembara Putri Gading Cempaka” by Agus Setiyanto. LITE: Jurnal Bahasa, Sastra, dan Budaya $17 \quad$ (2), 150-159. https://doi.org/10.33633/lite.v17i2.5049

Kutipan di atas menggambarkan sebuah tradisi khas kerajaan dalam memecahkan sebuah permasalahan. Tradisi tersebut adalah sayembara. Sayembara dalam konteks data di atas digelar dalam rangka mencarikan Putri Gading Cempaka seorang pendamping hidup sekaligus sebagai raja di kerajaan Sungai Serut. Sayembara tersebut boleh diikuti oleh siapa pun. Namun kenyataannya, sayembara tersebut hanya diikuti oleh para bangsawan, pangeran, juga raja dari negeri seberang. Hal itu tidak mengherankan mengingat menjadi seorang raja juga berarti siap memikul tanggung jawab yang besar. Orang-orang biasa atau rakyat kecil tentunya tidak memiliki nyali untuk turut andil dalam sayembara tersebut.

Tradisi sayembara tersebut mengandung banyak sekali nilai-nilai. Pertama, kegiatan sayembara yang diadakan pihak kerajaan menggambarkan bahwa sekuat apapun sebuah kerajaan, sebaik apapun seseorang, ia tetap membutuhkan pihak lain untuk dapat menjalani hidup dengan baik. Kesadaran tersebut tentunya akan melahirkan rasa kepedulian dan kesetiakawanan sosial yang tinggi pula dalam diri seseorang. Hal ini didasari oleh kesadaran bahwa sebagai manusia, kita tidak akan pernah bisa hidup tanpa bantuan orang lain.

Kedua, kegiatan sayembara akan melahirkan keputusan yang lebih baik. Hal ini dikarenakan dalam sayembara terdapat banyak pilihan, contoh dalam konteks data di atas, sayembara diadakan untuk mencari suami sekaligus raja bagi kerajaan Sungai Serut. Tentunya dengan sayembara yang diadakan akan menggerakkan para raja, pangeran dan orang-orang besar lainnya untuk mengikuti sayembara tersebut.

Di zaman moderen seperti sekarang, istilah sayembara memang sudah hampir tidak terdengar, tetapi konsepnya tetap ada dan dipertahankan. Sebagai contoh, ketika sebuah keluarga kehilangan anaknya, maka mereka berinisiatif menyebarkan berita kehilangan anak kepada masyarakat. Siapa saja yang dapat memberikan informasi tentang keberadaan anaknya akan diberikan imbalan yang sesuai. Demikian pula ketika keluarga kaya raya kehilangan anjingnya yang berharga, mereka memasang poster berbagai tempat yang mudah terlihat, seperti di pinggir jalan untuk mengabarkan kepada masyarakat bahwa siapa saja yang dapat menemukan anjing kesayangannya akan diberikan hadiah. Hal-hal semacam itu sering ditemui. Hal itu lumrah mengingat konsep sayembara ini memang sangat efektif sebagai salah satu solusi yang bisa digunakan untuk memecahkan masalah.

\title{
3.3 Kearifan Lokal Berwujud Nilai
}

Kearifan lokal yang terkandung di dalam naskah sandiwara Bengkulu Sayembara Putri Gading Cempaka juga banyak yang berwujud nilai-nilai. Nilai-nilai tersebut di antaranya adalah kebijaksanaan dan kepedulian sosial. Kebijaksanaan dimiliki oleh Sultan Iskandar Nan Tua, dan Penasihatnasihat sedangkan kepedulian sosial dimiliki oleh dayang istana.

\begin{abstract}
SULTAN ISKANDAR NAN TUA
Mantap dan terkendali? Bohong kamu Panglima! Berdasarkan laporan yang masuk ke saya langsung, ternyata masih ada dari rakyat kita yang justru merasa tidak aman dan nyaman karena sistem DOM yang Panglima terapkan. Bahkan saya dengar lagi, malah ada yang memisahkan diri. Dan saya tidak menginginkan daripada hal itu terjadi, Panglima! (Setiyanto, 2006:5)
\end{abstract}

Kutipan di atas menggambarkan ketegasan dan kebijaksanaan dari Sultan Iskandar Nan Tua selaku Raja dari kerajaan Sungai Serut. Pada data di atas terlihat ketegasan sang raja yang menyangkal penuturan Panglima kerajaan yang menyampaikan bahwa keadaan masyarakat kecil senantiasa diliputi ketenteraman. Padahal berdasarkan laporan yang diterima Baginda Raja, kondisi sebagian masyarakat masih memprihatinkan. Sikap sang raja juga merupakan bentuk kebijaksanaan sebagai pemimpin tertinggi kerajaan Sungai Serut karena sang raja selalu mengutamakan rakyatnya daripada pejabat istana. 
Febriyanto, D. \& Widodo, M., (2021). Local Wisdom in Bengkulu Play Script "Sayembara Putri Gading Cempaka” by Agus Setiyanto. LITE: Jurnal Bahasa, Sastra, dan Budaya $17 \quad$ (2), 150-159. https://doi.org/10.33633/lite.v17i2.5049

Kebijaksanaan juga dimiliki oleh Penasihatnasihat kerajaan Sungai Serut. Hal ini tergambar ketika Penasihatnasihat kerajaan menyampaikan sarannya terkait pergantian pimpinan kerajaan. Berikut ini data yang menggambarkan kebijaksanaan Penasihatnasihat kerajaan.

\section{PENASIHATNASIHAT}

Hamba sangat setuju, dan mendukung aspirasi para kaum pembesar kerajaan. Akan tetapi, semua itu kembali kepada kebijakan Baginda. Bukankah di alam yang demokratis ini, tidak ada paksaan kehendak? Namun, hendaknya amanat ini menjadi bahan pertimbangan bagi Baginda Sultan. (Setiyanto, 2006:13)

Data di atas menggambarkan kebijaksanaan dari Penasihatnasihat kerajaan mengenai keinginan Baginda Raja untuk menyudahi kepemimpinannya dan berencana menjadikan putera tunggalnya sebagai penerusnya. Kebijaksan penasihatnasihat kerajaan terlihat ketika ia dengan tenang memberikan masukan sekaligus nasihatnasihat kepada baginda raja mengenai kebimbangannya tersebut. Penasihatnasihat kerajaan menyampaikan agar sang raja memperhatikan semua saran yang telah disampaikan sebagai pertimbangan dalam mengambil keputusan. Hal itu perlu dilakukan agar ke depannya tidak ada pihak- pihak yang merasa dirugikan atas keputusan yang diambil oleh sang raja.

Adapun nilai kepedulian sosial digambarkan pengarang melalui tokoh Dayang. Hal ini dapat dilihat melalui kutipan berikut.

\section{DAYANG}

(KELUAR JOGED). "Oi, Tuan Putri nan sembilu, adakah gerangan nan merindu, hamba dayang disamping- mu, pintalah apa Tuanku mau." Ayolah Tuan Putri,. Bicaralah kepada hamba! Oh ya, hamba tahu, Tuan Putri perlu dihibur.... Baiklah Tuan Putri, hamba akan panggil penari kemari untuk menghibur Tuan Putri. (Setiyanto, 2006:33)

Kepedulian sosial tokoh Dayang terhadap Putri Cempaka sangat besar. Hal itu terlihat secara jelas melalui data di atas. Dayang terlihat sangat khawatir terhadap Putri Cempaka yang terlihat murung. Bahkan Dayang sampai mendesak sang putri untuk memberitahukan dirinya perihal masalah yang sampai membuat tuan putrinya murung. Kebijaksanaan dan kepedulian sosial adalah dua nilai yang sangat penting dimiliki orang setiap orang. Kebijaksanan akan menjadikan seseorang mampu memutuskan segala permasalahan dengan baik, sedangkan kepedulian sosial akan mempererat hubungan antarsesama.

\subsection{Kearifan Lokal Berwujud Nasihat}

Nasihat merupakan wujud kearifan lokal yang sering kita dengar dan saksikan. Nasihat biasanya disampaikan sebagai wujud kepedulian sekaligus sebagai bahan refleksi atas kesalahan yang telah dilakukan. Perihal nasihat juga tergambar ketika sang raja dipandang penasihat kerajaan melakukan kelalaian atas sikapnya.

\section{PENASIHAT}

Maaf Baginda Sultan, hamba selaku penasihat, sudah semestinya diajak konsultasi. Hamba kira, Baginda Sultan jangan asal comot, sebab ini nanti menyangkut kredibilitas kerajaan, apalagi Saudara Panglima ini sama sekali tidak memiliki latar belakang yang berhubungan dengan seluk beluk pengadilan, dan hamba takut, nanti banyak yang protes, Baginda! (Setiyanto, 2006:10)

'Kutipan di atas menggambarkan nasihat yang diberikan Penasihat kepada sang raja. Penasihat menganggap sikap raja yang tanpa pertimbangan langsung mengangkat penganti pejabat istana merupakan suatu kecerobohan. Oleh karena hal tersebut dapat memicu permasalahan, pejabat istana 
Febriyanto, D. \& Widodo, M., (2021). Local Wisdom in Bengkulu Play Script "Sayembara Putri Gading Cempaka” by Agus Setiyanto. LITE: Jurnal Bahasa, Sastra, dan Budaya $17 \quad$ (2), 150-159. https://doi.org/10.33633/lite.v17i2.5049

mencoba memberikan nasihat kepada sang raja agar tidak gegabah dalam mengambil sebuah keputusan. Segala keputusan yang diambil tanpa pertimbangan yang matang hanya akan melahirnya penyesalan di masa mendatang. Sikap penasihat yang seperti itu sejatinya adalah wujud kepeduliannya terhadap kerajaan.

Setiap pribadi adalah pemimpin. Minimal pemimpin bagi dirinya sendiri. Sebagai seorang pemimpin, sikap kehati-hatian itu sangat diperlukan dalam mengambil sebuah keputusan. Tidak menjadi persoalan manakala lama dalam memutuskan, asalkan hasil keputusannya berdampak baik untuk diri sendiri dan orang lain. Daripada cepat dalam mengambil keputusan, tapi ternyata keputusan yang diambil tidak matang sehingga merugikan diri sendiri dan orang lain. Sikap tergesa-gesa bagi seorang pemimpin adalah sikap yang tidak baik. Pemimpin harus melihat dari berbagai sudut pandang ketika ingin mengambil sebuah keputusan.

\subsection{Kearifan Lokal Berwujud Pandangan Hidup}

Pandangan hidup dapat disebut juga sebagai prinsip hidup. Prinsip hidup pada dasarnya selalu berpijak pada nilai-nilai kebenaran. Kearifan lokal berwujud pandangan hidup digambarkan pengarang melalui tokoh Bunda Ratu dan Putri Gading Cempaka.

\section{BUNDA RATU}

Tidak bisa begitu nanda, ... Ini namanya tidak adil. Menurut bunda, si bungsu harus diajak musyawarah, sebab biar bagaimana pun, si bungsu harus ikut andil dalam memberikan suaranya... Kalau suara kaum perempuan dipasung terus, akibatnya tidak baik .... (Setiyanto, 2006:40-41)

Kutipan di atas menggambarkan ketegasan sekaligus keteguhan Bunda Ratu dalam memegang prinsip hidup. Bunda Ratu merupakan sosok yang sangat menjunjung tinggi keadilan. Ia tidak bisa melihat keadilan dipermainkan. Selain itu, Bunda Ratu adalah orang yang meyakini kekuatan perempuan itu setara dengan laki-laki. Apabila perempuan selalu diremehkan, dan suaranya selalu dipasung, tidak pernah didengarkan, Bunda Ratu meyakini bahwa hal-hal tersebut akan membawa mereka ke dalam kubangan penderitaan.

Prinsip hidup Putri Gading Cempaka tak kalah kuatnya dengan prinsip sang ibu. Ia adalah wanita yang teguh membela kebenaran.

\section{PUTRI GADING CEMPAKA}

Interupsi Manda Mangku! Kenapa kita harus takut menghadapi kebenaran, dan takut kehilangan kekuasaan? Bagaimana dengan suara hamba dan juga Bunda Ratu? Jadi, maaf Manda Mangku, saya tetap berbeda pendapat. (Setiyanto, 2006:74)

Kutipan di atas dengan jelas memperlihatkan keteguhan dan ketegasan Putri Gading Cempaka dalam membela kebenaran. Ia adalah wanita yang tidak pernah takut mengorbankan apapun demi tegaknya kebenaran. Ia meyakini bahwa dengan menegakkan kebenaran, kemenangan yang sejati akan datang. Begitu pula sebaliknya, apabila seseorang dalam rangka mencapai tujuan berani mengorbankan kebenaran, sejatinya orang tersebut telah melemparkan dirinya sendiri ke jurang penderitaan. Ketegasan Putri Gading Cempaka seharusnya dapat dijadikan sebagai cambuk bagi setiap pribadi yang lemah pendirian. Kebenaran sudah seharusnya senantiasa dipertahankan bagaimanapun keadaan kita.

\subsection{Kearifan Lokal Berwujud Bahasa Daerah}

Naskah sandiwara Bengkulu Sayembara Putri Gading Cempaka banyak menghadirkan bahasa daerah di dalamnya. Bahasa daerah tersebut memberi warna tersendiri di dalam karyanya. Pada 
Febriyanto, D. \& Widodo, M., (2021). Local Wisdom in Bengkulu Play Script "Sayembara Putri Gading Cempaka” by Agus Setiyanto. LITE: Jurnal Bahasa, Sastra, dan Budaya $17 \quad$ (2), 150-159. https://doi.org/10.33633/lite.v17i2.5049

konteks naskah drama, setidaknya ada empat bahasa yang digunakan tokoh di dalam setiap percakapan atau dialog, bahasa Indonesia, bahasa Jawa, bahasa Sunda, dan bahasa Madura. Berikut ini salah satu data yang menggambarkan penggunakan bahasa daerah.

\begin{abstract}
ADIPATI SAMPANG
Mit amit Pakdhe, saya badhe nya Tanya, apa bener ini wilayah Sungai Semut tak iya? Ihok... Ihok... Ihok, terima kasih kalau begitu Wis Pakdhe, aku njaluk pamit. Tak lebonane Sungai Semut.... He wong Sungai Semut, iki Adipati Sampang sing teko, arep mboyong Gading Cempaka, tampanono dik! [Permisi Pakde, saya ingin bertanya, apa benar ini wilayah Sungai Semut, ya? Iya... Iya... Iya.. terima kasih kalau begitu. Sudah Pakde, saya minta (izin) pamit. Saya masuki Sungai Semut. Hai warga Sungai Semut, ini Adipati Sampang yang datang, ingin memboyong Gading Cempaka, terimalah Dik!] (MASUK JOGET)
\end{abstract}

(Setiyanto, 2006:26-27)

Kutipan di atas menggambarkan penggunaan bahasa Madura oleh tokoh Adipati Sampang. Adipati Sampang merupakan salah satu raja dari Madura yang tertarik untuk mengikuti sayembara perebutan Putri Gading Cempaka. Ia adalah seorang raja yang mudah berbaur dengan masyarakat dan memiliki selera humor cukup baik.

Kearifan lokal berwujud bahasa daerah yang dimunculkan pengarang memiliki makna yang sangat dalam. Pertama, pengarang ingin memberikan edukasi bahwa Indonesia sebagai negara kepulauan terbesar memiliki banyak sekali bahasa daerah. Bahasa daerah yang beragam itu merupakan kekayaan bangsa yang wajib dijaga bersama. Jangan sampai keberagaman itu justru dijadikan sebagai alat pemecah belah. Kedua, pengarang ingin membangun kesadaran bahwa keberagaman adalah bagian dari kehendak Tuhan yang tidak dapat dilawan. Oleh karena itu, kita harus menerimanya dengan penuh kebahagiaan dan sepatutnya memandan keberagaman sebagai sebuah anugerah yang besar.

Dengan menghadirkan bahasa daerah, pengarang juga memantik para pembaca sekaligus penikmat sandiwara agar tergerak mengetahui lebih dalam tentang bahasa daerah yang ada di Indonesia. Bahasa daerah sebagai salah satu kekayaan budaya bangsa harus senantiasa dijaga dan dilestarikan bersama. Jangan sampai karena mementingkan bahasa asing, kita mengabaikan dan menganggap rendah bahasa daerah. Pengarang menghendaki pembaca dan penikmat sastra menjadi pribadi yang berwawasan luas, khususnya mengenai kebangsaan.

\title{
4 Simpulan
}

Berdasarkan analisis yang telah dilakukan, dapat disimpulkan bahwa naskah sandiwara Bengkulu Sayembara Putri Gading Cempaka mengandung kearifan lokal yang beragam. Adapun kearifan lokal yang dimaksud adalah kearifan lokal berwujud: (1) pantangan dan kewajiban yang meliputi pantangan dan kewajiban seorang pemimpin dan pantangan mengotori sungai hingga membuat tidak terkontrolnya ekosistem lingkungan; (2) tradisi sayembara untuk mencari solusi dari permasalahan yang dihadapi; (3) nilai, meliputi tangung jawab, peduli sosial, dan tegas; (4) nasihat yang ditujukan untuk seorang pemimpin; (5) pandangan hidup, tentang kebijaksanaan dalam memandang alam demokrasi, peran wanita, dan praktik politik kotor; dan (6) bahasa daerah, di antaranya bahasa Madura, bahasa Jawa, dan bahasa Sunda. Kearifan lokal yang tertuang di dalam naskah sandiwara Bengkulu Sayembara Putri Gading Cempaka dapat dijadikan refleksi bagi segenap pembaca dalam menjalani kehidupan berbangsa dan bermasyarakat. 
Febriyanto, D. \& Widodo, M., (2021). Local Wisdom in Bengkulu Play Script "Sayembara Putri Gading Cempaka” by Agus Setiyanto. LITE: Jurnal Bahasa, Sastra, dan Budaya $17 \quad$ (2), 150-159. https://doi.org/10.33633/lite.v17i2.5049

\section{Referensi}

Damono, S. D. (2012). Sosiologi Sastra. Jakarta: Gramedia.

Febriyanto, D., Nurjana, K., Anista, E., \& Mardiansyah, D. (2021). Kearifan Lokal dalam Hikayat Komering Pitu Phuyang. Diglosia: Jurnal Kajian Bahasa, Sastra, Dan Pengajarannya, 4, $321-$ 334.

Gasong, D., Rajuati, S., \& Rumpa, L. D. (2015). Kearifan Lokal Dalam Cerita Rakyat Toraja Tulangdidi' Tinjauan Hermeneutik. Jurnal Keguruan Dan Ilmu Pendidikan, 4(3), 941-945. http://ukitoraja.ac.id/journals/index.php/jkip/article/view/51

Gemtou, E. (2014). Exploring the Possibilities of Postdramatic Theater as Educational Means. International Journal of Education and the Arts, 15(12), 1-15. https://doi.org/10.1177/1321103X0001500110

Hasanah, A., el al. (2016). Nilai-Nilai Karakter Sunda: Internalisasi Nilai-Nilai Sunda di Sekolah. Yogyakarta: Deepublish.

Jayapada, G., \& Kiptiyah, B. M. (2017). Kearifan Lokal dalam Cerita Rakyat sebagai Media Pendidikan Karakter untuk Membentuk Literasi Moral Siswa. BIBLIOTIKA: Jurnal Kajian Perpustakaan Dan Informasui, 60-62.

Kasmi, H. (2019). Nilai-Nilai Kearifan Lokal dalam Novel Tempat Paling Sunyi Karya Arafat Nur. Jurnal Metamorfosa, 7(2), 161-169.

Lubis, N. A., Gusti, R. B. S., \& Annisa. (2021). Analisis Nilai-nilai Kearifan Lokal dalam Novel Mangalua Karya Idris Pasaribu. Asas: Jurnal Sastra, 10(1), 74-84.

Maemunah, S. (2019). Kearifan Lokal dalam Novel Kalompang Karya Badrul Munir Chair serta Implikasinya Terhadap Pembelajaran Sastra di SMA. BAHASTRA: Jurnal Pendidikan Bahasa Dan Sastra Indonesia, 3(2), 237-240. https://journal.unnes.ac.id/sju/index.php/jpbsi/article/view/24018

Mariane, I. (2014). Kearifan Lokal Pengelolaan Hutan Adat. Jakarta:PT. Raja Grafindo Persada.

Muchtar, R. (2009). Harmonisasi Agama dan Budaya di Indonesia. Jakarta: Balai Penelitian dan Pengembangan Agama.

Ratna, N. K.(2015). Teori, Metode, dan Teknik Penelitian Sastra. Yogyakarta: Pustaka Pelajar.

Ridwan, N. A. (2007). Landasan Keilmuan Kearifan Lokal. Jurnal Studi Islam Dan Budaya, 5(1), 18.

Rohmadi, M., \& Yakub, N. (2017). Dasar-Dasar Penelitian Bahasa, Sastra, dan Pengajaran. Surakarta: Pustaka Briliant.

Sartini. (2004). Menggali Kearifan Lokal Nusantara. Jurnal Filsafat, 37(2), 111-120. https://jurnal.ugm.ac.id/wisdom/article/view/33910/20262 
Febriyanto, D. \& Widodo, M., (2021). Local Wisdom in Bengkulu Play Script "Sayembara Putri Gading Cempaka” by Agus Setiyanto. LITE: Jurnal Bahasa, Sastra, dan Budaya $17 \quad$ (2), 150-159. https://doi.org/10.33633/lite.v17i2.5049

Setiyanto, A. (2006). Kumpulan Naskah Sandiwara Bengkulu: Panggung Bangsawan. Yogyakarta: Gitanagari.

Tsai, S., Chang, T.-C., \& Huang, Y.-F. (2016). An Intelligent Recommendation System for Animation Scriptwriters ' Education. Eurasia Journal of Mathematics, Science \& Technology Education, 12(5), 1139-1151. https://doi.org/10.12973/eurasia.2016.1502a

Wildan, W. (2020). Kearifan Lokal dalam Novel Seulusoh Karya D. Kemalawati. Pendidikan Bahasa Dan Sastra, 1(2013), 7-24.

Yetti, E. (2019). Kearifan Lokal dalam Cerita Rakyat Nusantara: Upaya Melestarikan Budaya Bangsa. Mabasan, 5(2), 13-24. https://doi.org/10.26499/mab.v5i2.207 